\title{
Helmet CPAP to treat hypoxic pneumonia outside the ICU: an observational study during the COVID-19 outbreak
}

\author{
Andrea Coppadoro' , Annalisa Benini ${ }^{1}$, Robert Fruscio 1,2, Luisa Verga ${ }^{1}$, Paolo Mazzola ${ }^{1,2}$, Giuseppe Bellelli ${ }^{1,2}$, \\ Marco Carbone ${ }^{1,2}$, Giacomo Mulinacci ${ }^{1,2}$, Alessandro Soria' ${ }^{1}$, Beatrice Noè ${ }^{1,2}$, Eduardo Beck ${ }^{3}$, \\ Riccardo Di Sciacca', Davide Ippolito ${ }^{1}$, Giuseppe Citerio ${ }^{1,2}$, Maria Grazia Valsecchi², Andrea Biondi ${ }^{1,2}$, \\ Alberto Pesci ${ }^{1,2}$, Paolo Bonfanti ${ }^{1,2}$, Davide Gaudesi ${ }^{2}$, Giacomo Bellani ${ }^{1,2^{*}+}$ (D) and Giuseppe Foti ${ }^{1,2+}$
}

\begin{abstract}
Background: Respiratory failure due to COVID-19 pneumonia is associated with high mortality and may overwhelm health care systems, due to the surge of patients requiring advanced respiratory support. Shortage of intensive care unit (ICU) beds required many patients to be treated outside the ICU despite severe gas exchange impairment. Helmet is an effective interface to provide continuous positive airway pressure (CPAP) noninvasively. We report data about the usefulness of helmet CPAP during pandemic, either as treatment, a bridge to intubation or a rescue therapy for patients with care limitations (DNI).

Methods: In this observational study we collected data regarding patients failing standard oxygen therapy (i.e., non-rebreathing mask) due to COVID-19 pneumonia treated with a free flow helmet CPAP system. Patients' data were recorded before, at initiation of CPAP treatment and once a day, thereafter. CPAP failure was defined as a composite outcome of intubation or death.
\end{abstract}

Results: A total of 306 patients were included; $42 \%$ were deemed as DNI. Helmet CPAP treatment was successful in $69 \%$ of the full treatment and $28 \%$ of the DNI patients $(P<0.001)$. With helmet $\mathrm{CPAP}_{1} \mathrm{PaO}_{2} / \mathrm{FiO}_{2}$ ratio doubled from about 100 to $200 \mathrm{mmHg}(P<0.001)$; respiratory rate decreased from 28 [22-32] to 24 [20-29] breaths per minute, $P<0.001)$. C-reactive protein, time to oxygen mask failure, age, $\mathrm{PaO}_{2} / \mathrm{FiO}_{2}$ during CPAP, number of comorbidities were independently associated with CPAP failure. Helmet CPAP was maintained for 6 [3-9] days, almost continuously during the first two days. None of the full treatment patients died before intubation in the wards.

Conclusions: Helmet CPAP treatment is feasible for several days outside the ICU, despite persistent impairment in gas exchange. It was used, without escalating to intubation, in the majority of full treatment patients after standard oxygen therapy failed. DNI patients could benefit from helmet CPAP as rescue therapy to improve survival.

Trial Registration: NCT04424992

Keywords: Helmet continuous positive airways pressure CPAP, Noninvasive ventilation, Covid-19, Positive end expiratory pressure PEEP, Coronavirus pneumonia

*Correspondence: giacomo.bellani1@unimib.it

${ }^{\dagger}$ Giacomo Bellani and Giuseppe Foti contributed equally to this work

1 ASST Monza, San Gerardo Hospital, Monza, Italy

Full list of author information is available at the end of the article

\section{Background}

In the early months of 2020 a massive COVID-19 pneumonia outbreak hit Italy. During the pandemic, an overwhelming number of patients suffering from hypoxemic original author(s) and the source, provide a link to the Creative Commons licence, and indicate if changes were made. The images or other third party material in this article are included in the article's Creative Commons licence, unless indicated otherwise in a credit line to the material. If material is not included in the article's Creative Commons licence and your intended use is not permitted by statutory regulation or exceeds the permitted use, you will need to obtain permission directly from the copyright holder. To view a copy of this licence, visit http://creativecommons.org/licenses/by/4.0/. The Creative Commons Public Domain Dedication waiver (http://creativeco mmons.org/publicdomain/zero/1.0/) applies to the data made available in this article, unless otherwise stated in a credit line to the data. 
respiratory failure presented to hospitals' emergency rooms, burdening the health system to an unexpected extent. To face such a number of critically ill patients, intensive care beds were more than doubled, with an occupancy close to $100 \%$ [1].

One of the effective treatments for respiratory failure, particularly if applied early and in less severe patients, is noninvasive ventilation $[2,3]$. As an example, continuous positive airway pressure (CPAP) delivered noninvasively by helmet proved superior to non-rebreathing oxygen mask in community-acquired pneumonia $[4,5]$. The optimal treatment of COVID-19 pneumonia is still under debate, and some experts believe that providing a moderate level $\left(<10 \mathrm{cmH}_{2} \mathrm{O}\right)$ of Positive End-Expiratory Pressure (PEEP) can match patient's need during the first phase of the disease, albeit this must be balanced with the potential risk of delayed intubation [6-8], a topic on which a vigorous debate is ongoing [9].

The rationale for using helmet CPAP is that it is effective for treatment of respiratory failure, and presents many advantages as compared to noninvasive ventilation mask interface $[10,11]$. In fact, it is generally well tolerated, air leaks are rarely an issue and it is associated with low pressure ulcer complications, particularly for prolonged therapy [12]. When treating COVID-19 affected patients, the use of helmets might bear the additional advantage of reducing virus environment contamination $[13,14]$. Recent reports suggest that helmet CPAP can be effective for COVID-19 treatment [15-17], possibly combined with prone or lateral position [18-20]. In a multicenter cohort study, Aliberti et al. showed that helmet CPAP significantly increased $\mathrm{PaO} 2 / \mathrm{FiO} 2$ from oxygen administration alone, but that treatment failure was frequent, leading to intubation and mechanical ventilation of $44 \%$ of the patients [21].

Early recognition of patients at high risk of treatment failure is crucial, both for individual treatment and resources allocation. We present the outcomes associated with treatment of respiratory failure with helmet CPAP during the COVID-19 outbreak in our hospital consortium, an approach which has been widely applied in Northern Italy. The primary aim of the present study is to describe the effects of helmet CPAP treatment during the COVID-19 pandemic, identifying early predictors of CPAP failure. Secondary endpoints were the description of patients' outcomes based on the presence of ceiling of care.

\section{Methods}

This is a retrospective observational cohort study of COVID-19 patients treated with helmet CPAP from March 3 to April 3, 2020. Data were collected in a local online registry as part of the STORM study (Spallanzani
Institute Approval Number 84/2020; NCT04424992). Patients' consent was waived.

\section{Organizational aspects}

The study was conducted in the two hospitals of the ASST Monza (San Gerardo Hospital and Desio Hospital), which include a total of approximately 1200 beds, with about 35 ICU beds before COVID-19; ICU beds were increased up to one hundred during the surge. Several medical and surgical wards were converted in COVID19 wards, capable of applying noninvasive CPAP. Ward teams were composed by physicians and nurses from several disciplines.

Our medical emergency team (MET) is composed by an intensivist, a resident and a critical care nurse. During the pandemic, the MET was doubled during the surge and evaluated critical patients defining treatment limitations (i.e., do not intubate order, DNI) together with the floor physician and the patient. A protocol was instituted for the use of helmet CPAP in COVID-19 patients who failed standard oxygen therapy (Additional File 1: Fig. S1); failure of standard oxygen therapy was defined as one of the following during spontaneous breathing in non-rebreathing oxygen mask: $\mathrm{SpO}_{2}<93 \%$, respiratory rate $>24$ Breaths Per Minute (BPM), $\mathrm{pCO}_{2}<35 \mathrm{mmHg}$, thoraco-abdominal asynchronies.

\section{CPAP delivery system}

Our free-flow CPAP system (Additional File 1: Fig. S2) relied on a Venturi flow generator connected to the oxygen wall port; a value of $60 \mathrm{~L} / \mathrm{min}$ or above was the target for the fresh gas mixture flowing into the helmet [22]. $\mathrm{FiO}_{2}$ was verified by a $\mathrm{FiO}_{2}$ meter and adjusted based on oxygen saturation, while PEEP (i.e., CPAP level) within the helmet was maintained by an adjustable mechanical valve. Helmet CPAP was managed by floor physicians and nurses; the most severe patients were referred directly to the MET and managed on the hospital floor until intubation was required, while the others were treated by non-intensivist physician and screened once a day by the MET for possible ICU admission. Intravenous sedation was not used in the wards during helmet CPAP treatment, except for palliative care of terminal patients; some patients might have received oral benzodiazepines for relief of anxiety.

\section{Patients and data collection}

Inclusion criteria were: respiratory failure treated with helmet following standard oxygen therapy; and a positive Sars-CoV-2 nasopharyngeal swabs (real time polymerase chain reaction). Exclusion criteria were: futility of medical treatment due to expected short term death independent of COVID-19 pneumonia. 
The local online registry was developed with REDCap cloud 1.5 (Phase Inc). We collected data regarding past history and frailty [23]; date of symptoms onset, hospital admission and helmet CPAP start (day 1); blood gas analysis before and after (normally between one and two hours) helmet CPAP start; data regarding the use of helmet CPAP and oxygenation for the first week (day 2-8); laboratory exams; chest $\mathrm{x}$-ray examinations; need for intubation or ICU admission; treatment limitation decisions; and hospital outcome. The proportion of missing data for each variable is reported in Additional File 1: Table S1. An $\mathrm{FiO}_{2}$ of $90 \%$ was considered for $\mathrm{PaO}_{2} / \mathrm{FiO}_{2}$ ratio calculation during non-rebreathing oxygen mask therapy [24], albeit this estimation might lack of precision, particularly at higher values of minute ventilation [25]. Helmet CPAP failure was defined as a composite outcome of death or ICU admission for intubation. Albeit criteria for DNI decision or intubation were not protocolized, the MET was composed by a relatively small number of clinicians who shared decisions whenever possible and who met periodically to re-evaluate clinical strategies, decisions taken, controversies with colleagues, hence behaving consistently.

Safety of helmet CPAP treatment was evaluated by the presence of major adverse events, as recorded by the MET on the electronic medical records. Acute respiratory distress syndrome (ARDS) was defined following the Berlin definition [26].

\section{Statistical analysis}

Statistical analysis was performed using SPSS 17.0 (SPSS Inc). Data are reported as means \pm standard deviation (SD) or median [25-75 percentiles]. Continuous variables were tested for normality by Shapiro-Wilk test. Comparisons between patients' groups were performed by Mann-Whitney or independent sample t-Test; comparisons within the same patient were performed by Wilcoxon or paired-sample t-Test, as appropriate. Comparisons between two categorical variables were performed by Fisher's exact test (two-by-two comparisons) or by Chi-Square test (multiple classes). The analysis of helmet CPAP effects over $\mathrm{PaO}_{2} / \mathrm{FiO}_{2}$ ratio was conducted by repeated measures ANOVA, considering the $\mathrm{PaO}_{2} /$ $\mathrm{FiO}_{2}$ before and after CPAP as within-subjects variables, and severity of impairment in gas exchange or treatment failure as between-subjects variable. The multivariate analyses to identify independent factors associated with failure were performed by backward logistic regressions, considering CPAP failure as the dependent dichotomous variable. We analyzed the treatment failure using the Kaplan-Meier approach with stratification for $\mathrm{PaO}_{2} / \mathrm{FiO}_{2}$ ratio assuming that patients discharged alive from hospital before 28 days were alive on that day; differences in time curves were assessed by the Log-Rank test. The level of significance was 0.05 (two-tailed test) unless otherwise specified to account for multiple comparisons (Bonferroni correction).

\section{Results}

We enrolled in the study 306 consecutive patients (of the nearly 1500 COVID-19 treated) who failed oxygen mask therapy and underwent helmet CPAP treatment outside the ICU. Nearly $50 \%$ of the patients were younger than 65 years old and $\mathrm{PaO}_{2} / \mathrm{FiO}_{2}$ ratio with standard oxygen therapy was lower than 150 in two-thirds of the patients (209/306). The majority of the patients had no (30\%) or one $(30 \%)$ comorbidity; about half of the enrolled patients had hypertension (Table 1).

\section{Helmet CPAP treatment}

After failure of standard oxygen therapy, helmet CPAP treatment was started with a median PEEP of 5 [5-10] $\mathrm{cmH}_{2} \mathrm{O}$ and $\mathrm{FiO}_{2}$ of 50\% [50-90]. Helmet CPAP therapy led to a dramatic oxygenation improvement: $\mathrm{PaO}_{2} / \mathrm{FiO}_{2}$ ratio doubled from about 100 to $200 \mathrm{mmHg}(P<0.001$, Table 2). The median delay between the two arterial blood gases samplings (with standard oxygen mask and helmet CPAP) was rather short (median 3.5 [2-6] h), albeit we did not collect the exact timing at which CPAP was initiated between these two. The incidence of severe gas exchange impairment was markedly reduced by helmet CPAP (Fig. $1 \mathrm{a}, P<0.001$ by Chi-Square); the $\mathrm{PaO}_{2} /$ $\mathrm{FiO}_{2}$ ratio improvement was more pronounced among patients who showed a more pronounced gas exchange impairment (Fig. 1b, $P<0.001$ for helmet CPAP effect and for its interaction with $\mathrm{PaO}_{2} / \mathrm{FiO}_{2}$ class by $\mathrm{RM}$ Anova). A clinically significant reduction of respiratory rate was also present (from 28 [22-32] to 24 [20-29] BPM, $P<0.001)$. After beginning of helmet CPAP, $71 \%$ of patients presented ARDS criteria (severe 9\%; moderate $35 \%$; mild 27\%). Higher levels of C-reactive proteins were detected in patients whose gas exchange impairment was not improved by helmet CPAP treatment $(P=0.009$ by Anova, Fig. 2). Considering the entire population, helmet CPAP was maintained for 6 [3-9] days with a median PEEP of 10 [7-10] $\mathrm{cmH}_{2} \mathrm{O}$ and an $\mathrm{FiO}_{2}$ of 65 [50-90] \%. During the first two days after start of CPAP therapy, helmet was maintained in place for an average of $21 \mathrm{~h} /$ day, from days three to five for an average of $19 \mathrm{~h} /$ day. Patients could eat and drink during the CPAP breaks. After the initial oxygenation improvement with helmet CPAP therapy, $\mathrm{PaO}_{2} / \mathrm{FiO}_{2}$ ratio remained steadily impaired during the first week (202 [128-284] mmHg).

Helmet CPAP failure occurred in $48 \%$ of the patients, mostly in patients who had a treatment limitation decision $(72 \%$ vs. $31 \%$ in the full treatment group, $P<0.001$, 
Table 1. Characteristics of study patients, comparing successful helmet CPAP treatment vs. failure

\begin{tabular}{|c|c|c|c|c|}
\hline & All patients $\mathrm{N}=306$ & $\begin{array}{l}\text { Successful helmet CPAP } \\
\text { treatment } \mathrm{N}=159\end{array}$ & $\begin{array}{l}\text { Helmet CPAP failure } \\
\mathrm{N}=147\end{array}$ & $P$ value \\
\hline Age, years & $67[58-76]$ & $62[54-70]$ & $71[63-79]$ & $<0.001^{*}$ \\
\hline Sex male, $n .(\%)$ & $236(77)$ & $121(76)$ & $115(78)$ & 0.685 \\
\hline Body mass index, $\mathrm{kg} / \mathrm{m}^{2}$ & $26[24-30]$ & $26[24-30]$ & $25[24-30]$ & 0.631 \\
\hline Any comorbidity, n. (\%) & $228(74)$ & $99(62)$ & $129(88)$ & $<0.001^{*}$ \\
\hline Hypertension, n. (\%) & $159(52)$ & $69(43)$ & $90(61)$ & $0.002^{*}$ \\
\hline Comorbidities, $n$ & $1[0-2]$ & $1[0-2]$ & $2[1-3]$ & $<0.001^{*}$ \\
\hline Clinical Frailty Scale & $3[2-4]$ & $2[2,3]$ & $3[2-5]$ & $<0.001^{*}$ \\
\hline Symptoms onset to hospital admission, days & $7[4-10]$ & $7[5-10]$ & $7[4-10]$ & 0.464 \\
\hline Hospital admission to oxygen therapy failure, days & $1[0-2]$ & $1[0-3]$ & $0[0-2]$ & $0.001^{*}$ \\
\hline Do not intubate (DNI) order, $n(\%)$ & $130(42)$ & $37(23)$ & $93(63)$ & $<0.001^{*}$ \\
\hline White blood cells, $n^{*} 10^{3} / \mu \mathrm{L}$ & $7.38[5.58-10.11]$ & $7.03[5.65-8.4]$ & $7.71[5.35-11.28]$ & 0.052 \\
\hline Platelets, $n^{*} 10^{3} / \mu \mathrm{L}$ & $202[153-260]$ & 213 [164-265] & $183[142-256]$ & 0.027 \\
\hline C-reactive protein, $\mathrm{mg} / \mathrm{L}$ & $109[50-172]$ & $86[39-131]$ & 144 [67-207] & $<0.001^{*}$ \\
\hline Procalcitonin, ng/mL & $0.29[0.13-1.05]$ & $0.2[0.11-0.63]$ & $0.44[0.2-1.42]$ & $0.001^{*}$ \\
\hline Lactate dehydrogenase, U/L & $420[332-524]$ & $369[313-477]$ & $475[375-589]$ & $<0.001^{*}$ \\
\hline Creatinine, $\mathrm{mg} / \mathrm{dL}$ & $1[0.8-1.3]$ & $1[0.8-1.1]$ & $1.1[0.9-1.5]$ & $<0.001^{*}$ \\
\hline Urea, mg/dL & $39[28-61]$ & $32[25-44]$ & $50[33-84]$ & $<0.001^{*}$ \\
\hline
\end{tabular}

Univariate analysis of the association of relevant characteristics with CPAP failure. Data regarding the study population (All patients), the subgroup of patients successfully treated by helmet CPAP (Successful helmet CPAP treatment) and the subgroup of patients failing the helmet CPAP treatment (either intubated or nonsurvivors, depending on their ceiling-of-care status) are reported in the table

*Indicates persistence of statistically significant differences after Bonferroni correction for multiple comparisons $(p<0.003)$.

Table 2 Respiratory parameters collected with standard oxygen therapy and shortly after start of helmet CPAP

\begin{tabular}{llll}
\hline & $\begin{array}{l}\text { Standard } \\
\text { oxygen } \\
\mathbf{N}=\mathbf{3 0 6}\end{array}$ & $\begin{array}{l}\text { Helmet CPAP } \\
\mathbf{N}=\mathbf{3 0 6}\end{array}$ & P value \\
\hline $\begin{array}{l}\mathrm{PaO}_{2} / \mathrm{FiO}_{2} \text { ratio, } \\
\mathrm{mmHg}\end{array}$ & $103[79-176]$ & $202[146-284]$ & $<0.001^{*}$ \\
$\mathrm{O}_{2}$ saturation, \% & $95[91-97]$ & $98[96-99]$ & $<0.001^{*}$ \\
$\mathrm{PaCO}_{2}, \mathrm{mmHg}$ & $33[30-36]$ & $33[30.5-36]$ & $0.011^{*}$ \\
Resp rate, BPM & $28[22-32]$ & $24[20-29]$ & $<0.001^{*}$
\end{tabular}

BPM: breaths per minute; PEEP: positive end expiratory pressure; CPAP: continuous positive airway pressure; ARDS: acute respiratory distress syndrome *Indicates persistence of statistically significant differences after Bonferroni correction for multiple comparisons $(p<0.012)$

Fig. 3). CPAP failure was associated with several preexisting factors, such as advanced age, number of comorbidities and patient's frailty, a data which was missing for 120 patients (Table 1). CPAP failure was strongly associated with worse gas exchange (Table 3, Fig. 4), increased inflammatory markers, higher levels of serum lactate dehydrogenase and worse renal function (Table 1). Successful treatment with CPAP (i.e., hospital discharge without intubation) was associated with a nearly double oxygenation response to helmet CPAP therapy as compared to failure $\left(\mathrm{PaO}_{2} /\right.$ $\mathrm{FiO}_{2}$ increase +96 vs. $\left.+53 \mathrm{mmHg}, P=0.001\right)$. Helmet CPAP failure probability showed a different pattern if patients were stratified according to $\mathrm{PaO}_{2} / \mathrm{FiO}_{2}$ ratio measured either during standard oxygen or during helmet CPAP (Fig. 5). $\mathrm{A} \mathrm{PaO}_{2} / \mathrm{FiO}_{2}$ increasing above $200 \mathrm{mmHg}$ after positioning helmet CPAP $(68 \%$ in the successful vs. $32 \%$ in the failure groups, $P<0.001$ by Chi-Square; $P<0.001$ by Log Rank, Fig. 5$)$; and a respiratory rate returning to clinically acceptable levels (22 vs. $28 \mathrm{BPM}, P=0.007$, Table 2 ) were associated with successful helmet CPAP treatment.

A subgroup of patients $(n=42)$ was re-evaluated by the MET, on the first day of helmet CPAP therapy a few hours after initiation. At the receiving operator curve (ROC) analysis, the respiratory rate after few hours of helmet CPAP therapy was closely associated with CPAP success (AUC $=0.802$ [95\% CI $=0.66-0.94], P=0.001$ ). A respiratory rate below $30 \mathrm{BPM}$ showed $100 \%$ sensitivity for CPAP success; a respiratory rate above 24 showed $81 \%$ sensitivity and $76 \%$ specificity for CPAP failure.

The adoption of prone position sessions during helmet CPAP treatment was frequent (45\%).

No major adverse event associated with the use of helmet CPAP (e.g., deaths of full treatment patients 


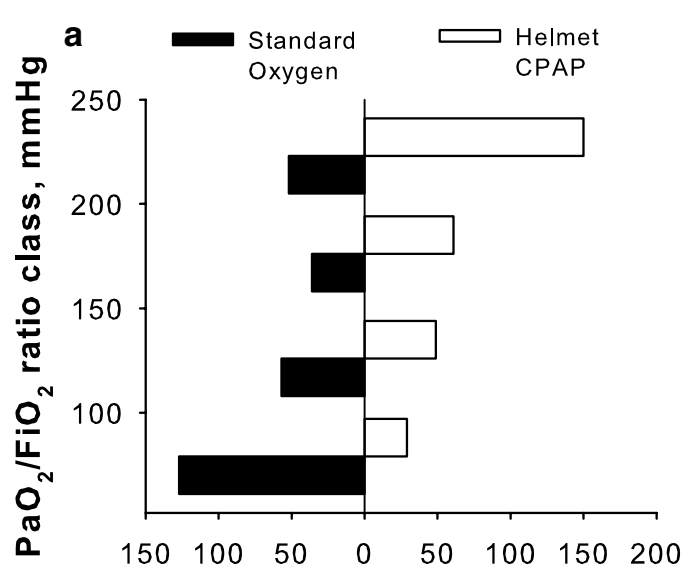

b

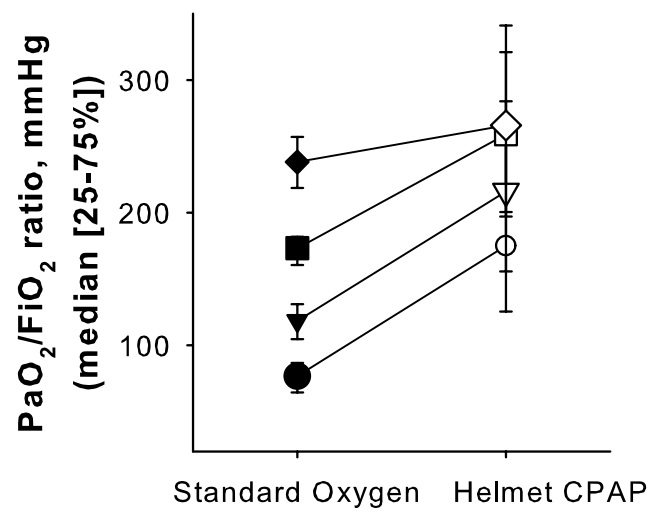

\section{Number of patients}

Fig. $1 \mathrm{PaO}_{2} / \mathrm{FiO}_{2}$ ratio increase with helmet CPAP therapy. The number of patients showing severe and moderate-to-severe gas exchange impairment is reduced shortly after start of helmet CPAP therapy $\left(P<0.001\right.$ by Chi-Square, panel a). $\mathrm{PaO}_{2} / \mathrm{FiO}_{2}$ ratio increase was higher among patients showing a more severe gas exchange impairment $(P<0.001$ for helmet CPAP effect and for its interaction with severity class by RM Anova, panel b)

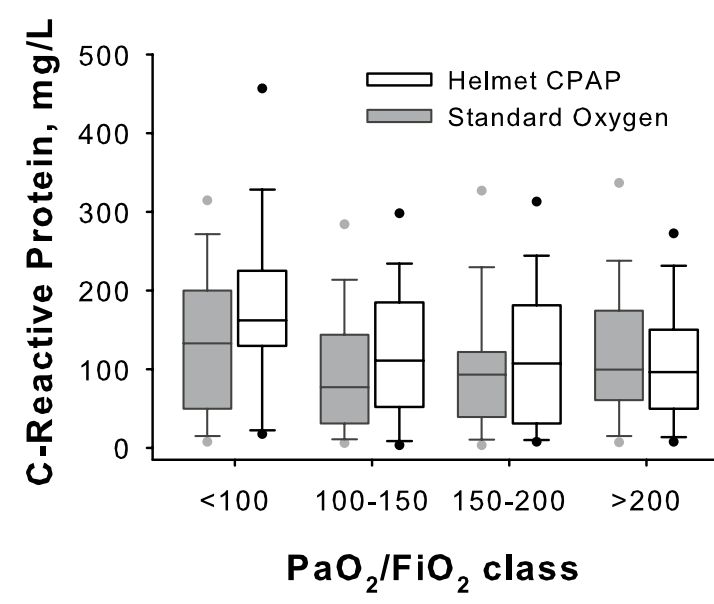

Fig. 2 C-reactive protein levels and gas exchange impairment severity. C-reactive protein levels were not associated with gas exchange impairment severity during standard oxygen therapy (grey boxes, $P=0.088$ by Anova). Patients showing a persistently severe gas exchange impairment despite helmet CPAP treatment (i.e., non-responders), showed higher levels of $C$-reactive proteins (white boxes, $P=0.009$ by Anova). Boxes represent median and $25-75$ percentiles; filled circles represent $5^{\text {th }}$ and $95^{\text {th }}$ percentiles

before intubation) was recorded by MET during the study period.

\section{Full treatment patients}

The majority of full treatment patients (122,69\%) did not require intubation and were successfully treated by helmet CPAP outside the ICU for 6 [4-9] days, with a PEEP

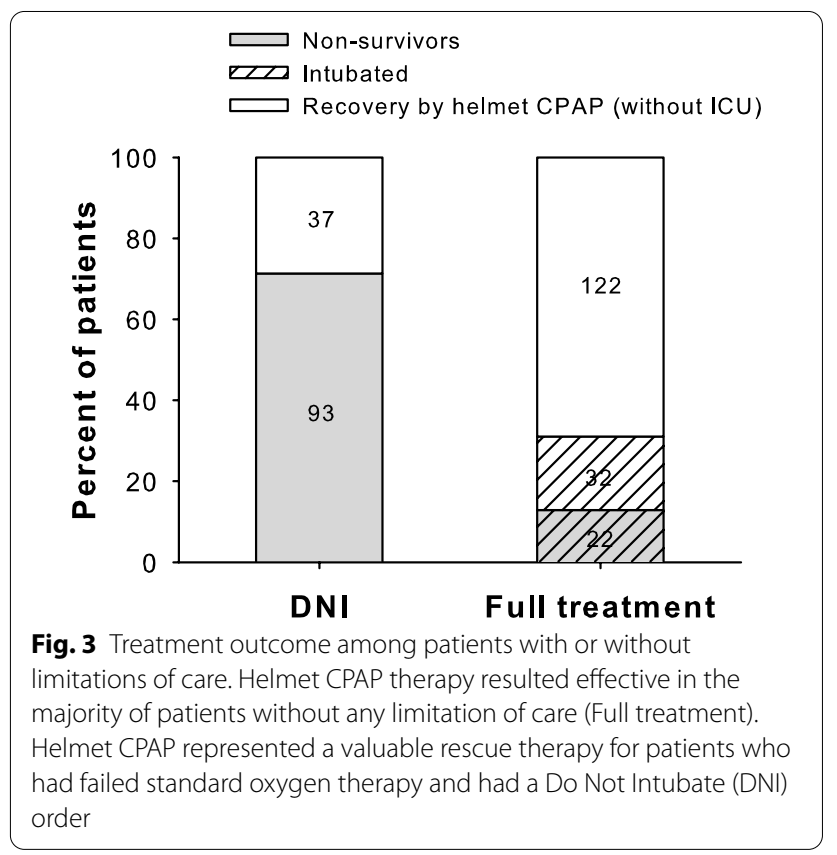

of 10 [5-10] $\mathrm{cmH}_{2} \mathrm{O}$ and a $\mathrm{FiO}_{2}$ of 50 [35-80] \%. Such patients were discharged from hospital after 14 [10-19] days. Patients requiring intubation $(54,31 \%)$ showed a higher heart rate on day one than those who did not (119, 68\%) (92 [83-102] BPM vs. 80 [72-90], $P<0.001)$. They were transferred to ICU for intubation after 4 [3-7] days of helmet CPAP treatment; in those patients, prone positioning was almost always attempted before intubation. 
Table 3 Respiratory parameters collected shortly after start of helmet CPAP in success vs failures

\begin{tabular}{|c|c|c|c|c|}
\hline & $\begin{array}{l}\text { All patients helmet CPAP } \\
N=306\end{array}$ & $\begin{array}{l}\text { Successful helmet CPAP } \\
\text { treatment } N=159\end{array}$ & $\begin{array}{l}\text { Helmet CPAP failure } \\
N=147\end{array}$ & $P$ value \\
\hline $\mathrm{PaO}_{2} / \mathrm{FiO}_{2}$ ratio, $\mathrm{mmHg}$ & 202 [146-284] & 252 [186-316] & 166 [114-243] & $<0.001^{*}$ \\
\hline $\mathrm{PaCO}_{2}, \mathrm{mmHg}$ & $33[30.5-36]$ & $33.2[31-36.2]$ & 32.5 [30-35.2] & 0.091 \\
\hline Resp rate, BPM & 24 [20-29] & 22 [19-25] & 28 [20-32] & $0.007^{*}$ \\
\hline PEEP, $\mathrm{cm} \mathrm{H}_{2} \mathrm{O}$ & $5[5-10]$ & $5[5-8]$ & $5[5-10]$ & $0.010^{*}$ \\
\hline $\begin{array}{l}\mathrm{PaO}_{2} / \mathrm{FiO}_{2} \text { ratio increase with CPAP, } \\
\mathrm{mmHg}\end{array}$ & $83[28-154]$ & $96[45-176]$ & 53 [18-115] & $<0.001^{*}$ \\
\hline ARDS diagnosis, $n(\%)$ & $178(71)$ & $78(62)$ & $100(79)$ & $0.006^{*}$ \\
\hline
\end{tabular}

Univariate analysis of the association of respiratory parameters collected shortly after CPAP start with CPAP failure during hospital stay

BPM: breaths per minute; PEEP: positive end expiratory pressure; CPAP: continuous positive airway pressure; ARDS: acute respiratory distress syndrome. Asterisks (*) indicates statistically significant differences after Bonferroni correction for multiple comparisons $(p<0.009)$

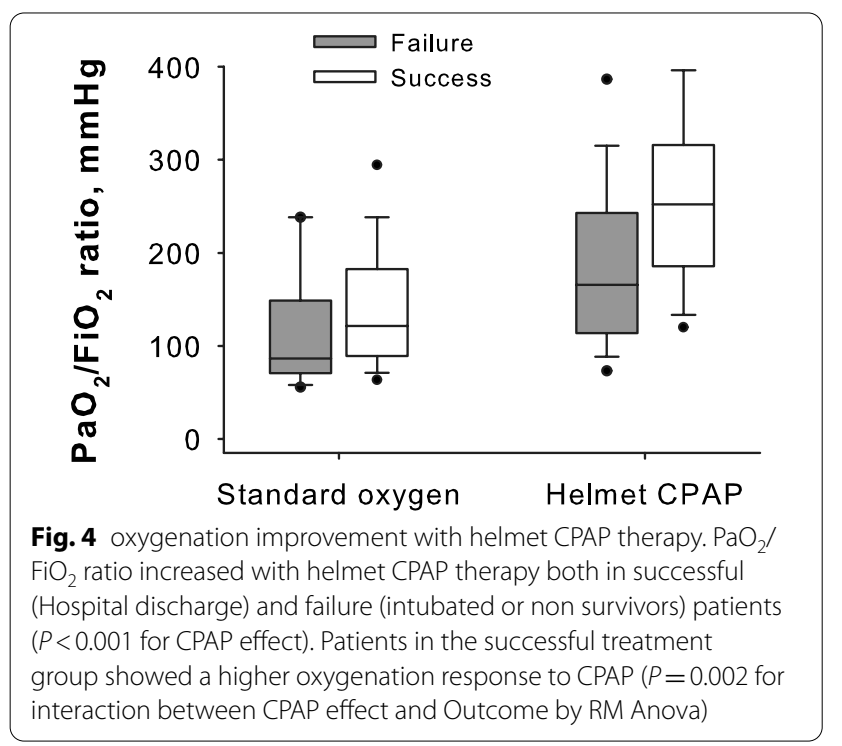

While $\mathrm{PaO}_{2} / \mathrm{FiO}_{2}$ ratio during standard oxygen therapy did not differ between the success and failure groups $(P=0.280)$, helmet CPAP therapy led to a higher $\mathrm{PaO}_{2} /$ $\mathrm{FiO}_{2}$ ratio in the success as compared to the failure group at the first measurement (257 [193-314] vs. 193 [133259] $P<0.001)$; this corresponded to a more pronounced response in oxygenation $\left(\mathrm{PaO}_{2} / \mathrm{FiO}_{2}\right.$ increase +100 [45-162] mmHg vs. +51 [12-99], $P=0.003)$. Among full treatment patients, a $\mathrm{PaO}_{2} / \mathrm{FiO}_{2}$ constantly above $150 \mathrm{mmHg}$ during the first week was associated with a probability of recovery without intubation of $91 \%$ $(P<0.001$ by Fisher's exact test). Hospital mortality among full treatment patients was $12.5 \%$ (22/176). All deaths occurred after ICU admission; patients who eventually died spent a shorter period on CPAP as compared to ICU survivors $(4[2-5]$ vs. 5 [4-8] days, $p=0.05)$, probably due to a more severe and aggressive disease.

\section{DNI patients}

A relevant number of patients (42\%) had a treatment limitation decision (DNI). A DNI order was associated with age higher than 75 years old, a higher number of comorbidities and worse oxygenation both before and after helmet CPAP as compared to the full treatment group $(P<0.001$ for all). A DNI order was strongly associated with helmet CPAP failure (which corresponds to mortality; $P<0.001)$. However, more than a quarter of DNI patients (28\%) had a favorable outcome with helmet CPAP treatment outside the ICU, despite a relevant oxygenation impairment on day one both with standard oxygen and with helmet CPAP therapy $\left(\mathrm{PaO}_{2} /\right.$ $\mathrm{FiO}_{2}$ ratio 104 [81-180] and 224 [151-319], respectively; $P<0.001$ for difference). Successful treatment among DNI patients was associated with younger age $(P=0.023)$ and lower comorbidities $(P=0.03)$.

\section{Multivariate analysis}

Factors included in the model, to predict CPAP failure were: age, sex, number of comorbidities, C-reactive protein, body temperature on day one, time to oxygen mask failure, $\mathrm{PaO}_{2} / \mathrm{FiO}_{2}$ ratio and $\mathrm{PaCO}_{2}$ both during standard oxygen and at the first measurement during helmet CPAP. At the backward logistic regression analysis, $\mathrm{C}$-reactive protein, time to oxygen mask failure, age, $\mathrm{PaO}_{2} / \mathrm{FiO}_{2}$ ratio collected during helmet CPAP treatment and number of comorbidities were independently associated with helmet CPAP failure (Table 4). The other tested factors (sex, body temperature, $\mathrm{PaO}_{2} /$ $\mathrm{FiO}_{2}$ ratio and $\mathrm{PaCO}_{2}$ during standard oxygen treatment, $\mathrm{PaCO}_{2}$ measured during CPAP) did not emerge as independent predictors of failure.

The list of factors entered in the backward analysis is reported in Additional File 1: Table S2. The results of a similar multivariate analysis including the $\mathrm{PaO}_{2} / \mathrm{FiO}_{2}$ 


\section{a}

$\mathrm{PaO}_{2} / \mathrm{FiO}_{2}$ measured during

Standard oxygen

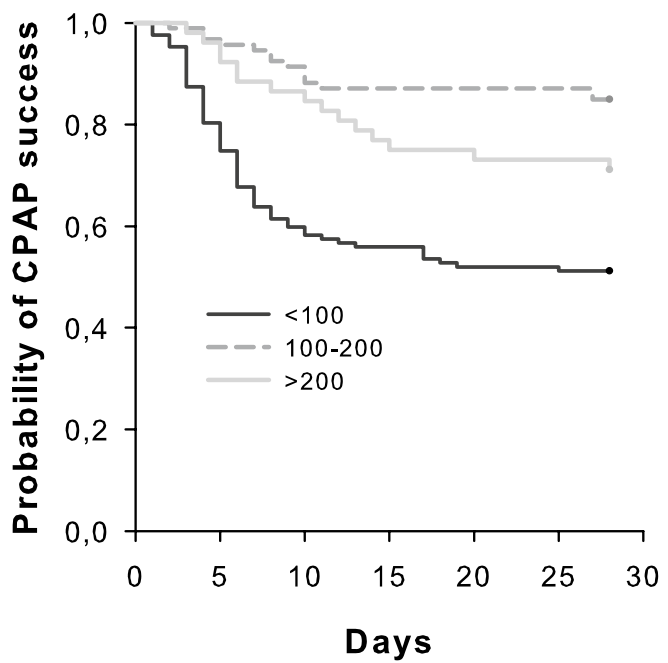

b

$\mathrm{PaO}_{2} / \mathrm{FiO}_{2}$ measured during

Helmet CPAP

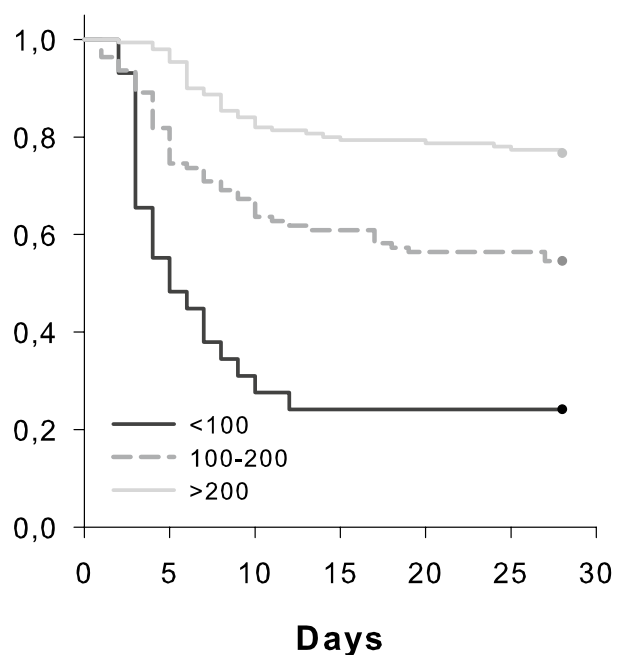

Fig. 5 Helmet CPAP failure at 28 days. Probability of helmet CPAP failure at 28 days is presented stratifying the same population of patients depending on $\mathrm{PaO}_{2} / \mathrm{FiO}_{2}$ ratio measured either during standard oxygen (panel a) or during helmet CPAP (panel b). While a PaO $/ 2 / \mathrm{FiO}_{2}$ ratio below $100 \mathrm{mmHg}$ with standard oxygen therapy is a weak predictor of failure (50\% probability), showing the same oxygenation impairment during helmet CPAP is associated with a high probability of failure ( $80 \%, P<0.001$ by Log Rank for both)

Table 4 Multivariate analysis of factors associated with helmet CPAP failure

\begin{tabular}{lll}
\hline Factor $^{\mathbf{a}}$ & P value & Odds ratio [95\% C.I.] \\
\hline C-reactive protein, mg/L & 0.001 & $1.006[1.003-1.010]$ \\
Hospital admission to oxygen therapy failure, days & 0.001 & $0.775[0.661-0.908]$ \\
Age, years & 0.002 & $1.054[1.020-1.089]$ \\
$\mathrm{PaO}_{2} / \mathrm{FiO}_{2}$ ratio (helmet CPAP), $\mathrm{mmHg}$ & 0.003 & $0.995[0.991-0.998]$ \\
$\mathrm{Comorbidities,} n$ & 0.005 & $1.582[1.147-2.182]$ \\
\hline
\end{tabular}

CPAP: continuous positive airway pressure

a factors entered in the backward regression model and removed due to lack of statistical significance $(P>0.05)$ : sex, body temperature, $\mathrm{PaO} / \mathrm{FiO} \mathrm{O}_{2}$ ratio and $\mathrm{PaCO} \mathrm{O}_{2}$ during standard oxygen treatment, $\mathrm{PaCO}_{2}$ measured during CPAP. C-reactive protein, time to oxygen mask failure, age, $\mathrm{PaO} / \mathrm{FiO}{ }_{2}$ ratio collected during helmet $\mathrm{CPAP}$ treatment and number of comorbidities were independently associated with helmet CPAP failure.

ratio change due to helmet CPAP in place of the $\mathrm{PaO}_{2} /$ $\mathrm{FiO}_{2}$ ratio measured during helmet CPAP are reported in Additional File 1: Table S3.

\section{Discussion}

In this observational study, we present the outcomes of helmet CPAP therapy for acute respiratory failure during the COVID-19 pandemic in a large Italian center. Helmet CPAP therapy outside ICU was feasible for several days (approximately one week), despite a severe gas exchange impairment. It was safely used to improve oxygenation and reduce respiratory distress (indirectly assessed, in a subset of patients, by respiratory rate) on the hospital floor, representing an intermediatelevel therapy to prevent intubation or ICU admission in nearly $70 \%$ of the full treatment patients. In DNI patients who failed standard oxygen therapy, a rescue trial with helmet CPAP represented a last treatment option with low invasiveness, which might have contributed to the observed 30\% survival.

In our hospitals, we have been using helmet CPAP since several years to apply PEEP during respiratory failure outside the ICU. Our approach to COVID-19 pneumonia, as in other types of pneumonia before the outbreak, is based on the rationale that PEEP and $\mathrm{FiO}_{2}$ are the cornerstones of respiratory support when nonrebreathing oxygen mask fails and can be delivered 
noninvasively, safely and effectively on the hospital floor by helmet CPAP. Therefore, helmet CPAP represented a natural and valuable choice to face the pandemic and limit the need for intubation.

A free-flow venturi system is simple to set up and operate; a refresh course was provided to instruct floor personnel, allowing us to rapidly escalate the treatment to hundreds of hypoxemic patients. In comparison with "classical" pressure support, the use of free flow helmet CPAP has the main advantages of not requiring a ventilator (whose shortage represented a major issue during pandemics) and not presenting any issue of patient-ventilator synchrony, even in the presence of leaks, elevated respiratory rate, patient movement and so forth. Taking advantage of a nurse-managed optimization bundle, helmet CPAP was well tolerated for many hours a day (almost continuously during the first days) [14], without relevant pressure ulcers [22].

All the enrolled patients were in the need of upscale treatment, either for hypoxemia or respiratory distress; however, it was crucial to carefully select and minimize the number of patients undergoing intubation and to have a safe bridge for those in whom intubation had to be postponed for logistical reasons. Helmet CPAP led to a marked and persistent oxygenation improvement in both full treatment and DNI patients, possibly indicating lung recruitment [27]. Ventilator effort was also reduced, as shown by lower respiratory rate shifting toward normal values after start of helmet CPAP therapy. Unfortunately, the way in which clinicians measured respiratory rate was not specified a priori, standardized or even recorded and might be affected by several limitations [28]. Hence, helmet CPAP might have reduced the so-called patient self-inflicted lung injury, whose putative existence and clinical is a matter of debate $[9,29]$. In this respect it must be also noted that a limitation inherent to the use of helmet is the inability of monitoring tidal volume, an important parameter to predict NIV failure [30].

The criteria to define standard oxygen therapy failure were quite conservative, leading to an early delivery of PEEP to hypoxemic patients. We cannot exclude that few patients could have been treated with non-rebreathing mask for longer periods of time; however, the persistent oxygenation impairment over the study days (median $\mathrm{PaO}_{2} / \mathrm{FiO}_{2}$ ratio below 200) and the high $\mathrm{FiO}_{2}$ need after start of helmet CPAP suggest worsening conditions, which would necessarily lead to escalate therapy.

The vast majority of full treatment patients (about $70 \%)$ was successfully treated with helmet CPAP without escalating to intubation, suggesting that a prolonged helmet CPAP treatment is effective for COVID-19 respiratory failure with a 24/7 availability of the MET. A $\mathrm{PaO}_{2} /$ $\mathrm{FiO}_{2}$ ratio above $150 \mathrm{mmHg}$ during helmet therapy was associated with a positive predictive value of $91 \%$ for treatment success. At the multivariate analysis, a lower $\mathrm{PaO}_{2} / \mathrm{FiO}_{2}$ value measured shortly after start of helmet CPAP was associated with failure, independent from age. Taken together, such data suggest that a helmet CPAP trial might provide useful information to the clinician about the evolution of the respiratory failure: simple markers such as a clear oxygenation improvement shortly after start of CPAP, a respiratory rate falling below 24 BPM within few hours, a $\mathrm{PaO}_{2} / \mathrm{FiO}_{2}$ persistently above 150 during the days, indicate that the patient can be treated effectively by helmet CPAP and possibly outside the ICU. In a previous trial, Patel's et al. enrolled full treatment patients needing CPAP and compared helmet with face mask, showing a much lower need for intubation with helmets (18\% vs. $61 \%$ ) [10]. The $31 \%$ failure rate recorded in our population is slightly higher than Patel's trial; possible explanations for the higher failure recorded in our population may be 1) the lack of a proven therapy for COVID-19 patients (either etiological or supportive, since steroids were not consistently used in March, 2020) and 2) the inability of replicating in the hospital ward the typical ICU tight monitoring for a vast number of patients.

The benefits of helmet CPAP therapy were evident also in the DNI group, where this strategy might have contributed to the $30 \%$ survival of DNI patients, who had no other treatment option for respiratory failure. The older age and the higher number of comorbidities suggest that preexisting conditions were the major culprits for failure in the DNI group, limiting the benefits of therapies focused on respiratory support such as helmet CPAP.

We acknowledge that we cannot draw definite conclusions about the timing and the effectiveness of CPAP therapy due to the observational nature of our data. However, a randomized trial comparing the use of CPAP vs. early intubation was not feasible during the pandemic for the shortage of ICU beds and might be considered unethical under different perspectives, due to the different invasiveness and risks for patients treated by CPAP as compared to intubation.

A different and widely used option to treat hypoxemic patients unresponsive to non-rebreathing oxygen mask are high flow nasal cannula (HFNC) [31]. We chose helmet CPAP as noninvasive respiratory support device for several reasons. First, HFNC provide a PEEP level much lower than CPAP, possibly representing a "low-dose" therapy for patients affected by severe gas exchange impairment. Second, the need for a dedicated heating and humidifying system with HFNC limited the use on a restricted number of patients, while active humidification may not be mandatory when spontaneously breathing a mixture of medical (dry) and ambient 
gas as within a Venturi based helmet CPAP. Third, the use of HFNC presented concerns for staff and environment contamination due to droplet spread, while helmet CPAP was the ideal device to limit droplet diffusion when using a HEPA filter on the outlet gas port [14]. Lastly, the MET and floor staff were already familiar with helmet CPAP, which has been used outside the ICU for many years in our hospital.

A limitation of our approach is therefore that the failure rate might not be the same if this technique was applied in other contexts, with difference experience, protocols or patients selection. Another limitation is that data were collected during a specific pandemic: Adherence to hospital protocols was more difficult due to the increased clinical burden; some patients may have received intubation later than usual due to ICU bed shortage; DNI orders may have been used more often than usual, denying ICU trials in elderly patients; data about patient comfort with the selected CPAP interface were not collected. Finally, the threshold and predictive values which we report (e.g., for $\mathrm{PaO} 2 / \mathrm{FiO} 2$ and respiratory rate) were not evaluated prospectively. All the presented factors may limit the generalizability of our data to patients affected by respiratory failure due to other etiologies. On the other side, the need to treat such a huge number of respiratory failure patients outside the ICU proved that helmet CPAP is a feasible and effective choice.

\section{Conclusions}

We showed that treatment of acute respiratory failure patients outside the ICU is feasible with helmet CPAP for many days, despite a persistent relevant degree of gas exchange impairment. Treatment was also effective, leading to a marked oxygenation improvement; helmet CPAP therapy was associated with a good outcome in the vast majority of full treatment patients and an effective rescue for a limited but significant proportion of DNI patients.

\section{Supplementary Information}

The online version contains supplementary material available at https://doi. org/10.1186/s13054-021-03502-y.

Additional file 1. A PDF (portable document format) file containing two figures (e-Figure 1, 2) and three tables (e-Table 1, 2 and 3).

\section{Abbreviations}

ARDS: Acute respiratory distress syndrome; BPM: Breaths per minute; COVID19: Novel coronavirus disease; CPAP: Continuous positive airways pressure; DNI: Do not intubate; HFNC: High flow nasal cannula; ICU: Intensive care unit; MET: Medical emergency team; PEEP: Positive end expiratory pressure.

\section{Acknowledgements}

We are grateful to Silvia Mori, PhD, Filippo Serra, MD, Michela Di Pierro, MD, Chiara Mottadelli, MD, Andrea Palermo, MD for data collection support.
Authors' contributions

$A C, G B$ and GF designed the study; $A C, A B, R F, L M, P M, G i u B, M C, G M, A S, B N$, $E B, R D S, D I, G C, M G V, A B, A P, P B, D G$ and $G B$ contributed to data collection; AC had full access to all of the data in the study and takes responsibility for the integrity of the data; $A C$ analyzed the data; $A C$ and GB drafted the manuscript; all authors revised, read and approved the final manuscript.

\section{Funding}

This paper was supported solely by internal fundings of the University of Milan-Bicocca. We acknowledge that this research was partially supported by the Italian Ministry of University and Research (MIUR) - Department of Excellence project PREMIA (PREcision Medlcine Approach: bringing biomarker research to clinic).

\section{Availability of data and materials}

The datasets used and analyzed during the current study are available from the corresponding author after obtaining the approval of the Spallanzani Institute ethical committee.

\section{Ethics approval and consent to participate}

Human participants were involved in this research; the study was conducted in accordance with the Declaration of Helsinki. Data were collected as part of the STORM study (Spallanzani Institute approval number 84/2020; NCT04424992). Patients' consent was waived.

\section{Consent for publication}

Not applicable.

\section{Competing interests}

AC has a patent and received consultancy fees from Flowmeter for a topic possibly related to this article; GB has a patent and received consultancy fees from Flowmeter, lecturing fees from Dimar SRL and Intersugical SPA for a topic possibly related to this article; GF received lecturing fees from Dimar SRL. Other authors have no COI to disclose no conflict of interest.

\section{Author details}

${ }^{1}$ ASST Monza, San Gerardo Hospital, Monza, Italy. ${ }^{2}$ Department of Medicine and Surgery, University of Milan-Bicocca, Via Cadore 48, Monza, MB, Italy.

${ }^{3}$ ASST Monza, Desio Hospital, Desio, Italy.

Received: 10 October 2020 Accepted: 10 February 2021

Published online: 24 February 2021

\section{References}

1. Grasselli G, Pesenti A, Cecconi M. Critical Care Utilization for the COVID-19 Outbreak in Lombardy, Italy: early experience and forecast during an emergency response. JAMA. 2020. https://doi.org/10.1001/ jama.2020.4031.

2. Bellani G, Laffey JG, Pham T, Madotto F, Fan E, Brochard L, et al. Noninvasive ventilation of patients with acute respiratory distress syndrome. Insights from the LUNG SAFE study. Am J Respir Crit Care Med. 2017;195:67-77.

3. Cabrini L, Landoni G, Oriani A, Plumari VP, Nobile L, Greco M, et al. Noninvasive ventilation and survival in acute care settings: a comprehensive systematic review and metaanalysis of randomized controlled trials. Crit Care Med. 2015;43:880-8.

4. Cosentini R, Brambilla AM, Aliberti S, Bignamini A, Nava S, Maffei A, et al. Helmet continuous positive airway pressure vs oxygen therapy to improve oxygenation in community-acquired pneumonia: a randomized, controlled trial. Chest. 2010;138:114-20.

5. Brambilla AM, Aliberti S, Prina E, Nicoli F, Del Forno M, Nava S, et al. Helmet CPAP vs. oxygen therapy in severe hypoxemic respiratory failure due to pneumonia. Intensive Care Med. 2014;40:942-9.

6. Alhazzani W, Moller MH, Arabi YM, Loeb M, Gong MN, Fan E, et al. Surviving Sepsis Campaign: guidelines on the management of critically ill adults with Coronavirus Disease 2019 (COVID-19). Intensive Care Med. 2020;46:854-87. 
7. Gattinoni L, Chiumello D, Caironi P, Busana M, Romitti F, Brazzi L, et al. COVID-19 pneumonia: different respiratory treatments for different phenotypes? Intensive Care Med. 2020;46:1099-102.

8. Gattinoni L, Coppola S, Cressoni M, Busana M, Rossi S, Chiumello D. COVID-19 Does not lead to a "typical" acute respiratory distress syndrome. Am J Respir Crit Care Med. 2020;201:1299-300.

9. Tobin MJ, Laghi F, Jubran A. P-SILI is not justification for intubation of COVID-19 patients. Ann Intensive Care. 2020a; 10:105.

10. Patel BK, Wolfe KS, Pohlman AS, Hall JB, Kress JP. Effect of Noninvasive ventilation delivered by helmet vs face mask on the rate of endotracheal intubation in patients with acute respiratory distress syndrome: a randomized clinical trial. JAMA. 2016;315:2435-41.

11. Ferreyro BL, Angriman F, Munshi L, Del Sorbo L, Ferguson ND, Rochwerg $B$, et al. Association of noninvasive oxygenation strategies with all-cause mortality in adults with acute hypoxemic respiratory failure: a systematic review and meta-analysis. JAMA. 2020. https://doi.org/10.1001/ jama.2020.9524

12. Antonelli M, Conti G, Pelosi P, Gregoretti C, Pennisi MA, Costa R, et al. New treatment of acute hypoxemic respiratory failure: noninvasive pressure support ventilation delivered by helmet-a pilot controlled trial. Crit Care Med. 2002;30:602-8.

13. Vitacca M, Nava S, Santus P, Harari S. Early consensus management for non-ICU acute respiratory failure SARS-CoV-2 emergency in Italy: from ward to trenches. Eur Respir J. 2020. https://doi.org/10.1183/13993 003.00632-2020.

14. Lucchini A, Giani M, Isgro S, Rona R, Foti G. The, "helmet bundle" in COVID19 patients undergoing non invasive ventilation. Intensive Crit Care Nurs. 2020. https://doi.org/10.1016/j.iccn.2020.102859.

15. Duca A, Memaj I, Zanardi F, Preti C, Alesi A, Della Bella L, et al. Severity of respiratory failure and outcome of patients needing a ventilatory support in the Emergency Department during Italian novel coronavirus SARS-CoV2 outbreak: Preliminary data on the role of Helmet CPAP and Non-Invasive Positive Pressure Ventilation. EClinicalMedicine. 2020. https ://doi.org/10.1016/j.eclinm.2020.100419.

16. Rali AS, Howard C, Miller R, Morgan CK, Mejia D, Sabo J, et al. Helmet CPAP revisited in COVID-19 pneumonia: a case series. Can J Respir Ther. 2020;56:32-4.

17. Armirfarzan H, Shanahan JL, Schuman R, Leissner KB. Helmet CPAP: how an unfamiliar respiratory tool is moving into treatment options during COVID-19 in the US. Ther Adv Respir Dis. 2020. https://doi. org/10.1177/1753466620951032.

18. Longhini F, Bruni A, Garofalo E, Navalesi P, Grasselli G, Cosentini R, et al. Helmet continuous positive airway pressure and prone positioning: a proposal for an early management of COVID-19 patients. Pulmonology. 2020;26:186-91.

19. Coppo A, Bellani G, Winterton D, Di Pierro M, Soria A, Faverio P, et al. Feasibility and physiological effects of prone positioning in non-intubated patients with acute respiratory failure due to COVID-19 (PRON-COVID): a prospective cohort study. Lancet Respir Med. 2020;8:765-74.

20. Retucci M, Aliberti S, Ceruti C, Santambrogio M, Tammaro S, Cuccarini F, et al. Prone and lateral positioning in spontaneously breathing patients with COVID-19 pneumonia undergoing noninvasive helmet CPAP treatment. Chest. 2020. https://doi.org/10.1016/j.chest.2020.07.006.

21. Aliberti S, Radovanovic D, Billi F, Sotgiu G, Costanzo M, Pilocane T, et al. Helmet CPAP treatment in patients with COVID-19 pneumonia: a multicenter, cohort study. Eur Respir J. 2020. https://doi.org/10.1183/13993 003.01935-2020.

22. Bellani G, Patroniti N, Greco M, Foti G, Pesenti A. The use of helmets to deliver non-invasive continuous positive airway pressure in hypoxemic acute respiratory failure. Minerva Anestesiol. 2008;74:651-6.

23. Rockwood K, Theou O. Using the clinical frailty scale in allocating scarce health care resources. Can Geriatr J. 2020;23:210-5.

24. Instructions to complete the CRF for the EPIC II study, last accessed on 2020 October 28th [https://www.intensive.org/epic2/Documents/Estim ation\%20of\%20PO2\%20and\%20FiO2.pdf]

25. Farias ERL, Zidulka A. Delivery of high inspired oxygen by face mask. J Crit Care. 1991:6:119-24.

26. Ranieri VM, Rubenfeld GD, Thompson BT, Ferguson ND, Caldwell E, Fan $\mathrm{E}$, et al. Acute respiratory distress syndrome: the Berlin Definition. JAMA. 2012;307:2526-33.

27. Mauri T, Spinelli E, Scotti E, Colussi G, Basile MC, Crotti S, et al. Potential for lung recruitment and ventilation-perfusion mismatch in patients with the acute respiratory distress syndrome from coronavirus disease 2019. Crit Care Med. 2020:48:1129-34.

28. Krieger B, Feinerman D, Zaron A, Bizousky F. Continuous noninvasive monitoring of respiratory rate in critically ill patients. Chest. 1986;90:632-4.

29. Tobin MJ, Laghi F, Jubran A. Caution about early intubation and mechanical ventilation in COVID-19. Ann Intensive Care. 2020b. https://doi. org/10.1186/s13613-020-00692-6.

30. Carteaux G, Millan-Guilarte T, De Prost N, Razazi K, Abid S, Thille AW, et al. Failure of noninvasive ventilation for de novo acute hypoxemic respiratory failure: role of tidal volume. Crit Care Med. 2016;44:282-90.

31. Frat JP, Thille AW, Mercat A, Girault C, Ragot S, Perbet S, et al. High-flow oxygen through nasal cannula in acute hypoxemic respiratory failure. $\mathrm{N}$ Engl J Med. 2015;372:2185-96.

\section{Publisher's Note}

Springer Nature remains neutral with regard to jurisdictional claims in published maps and institutional affiliations.
Ready to submit your research? Choose BMC and benefit from:

- fast, convenient online submission

- thorough peer review by experienced researchers in your field

- rapid publication on acceptance

- support for research data, including large and complex data types

- gold Open Access which fosters wider collaboration and increased citations

- maximum visibility for your research: over $100 \mathrm{M}$ website views per year

At BMC, research is always in progress.

Learn more biomedcentral.com/submissions 